\title{
RATED POWER DETERMINATION FOR AUTONOMOUS MICRO COMBINED HEAT AND POWER AND RECHARGEABLE BATTERY SYSTEM
}

\author{
A. Fedotov', G. Vagapov*, L. Grackova²** and R. Abdullazyanov ${ }^{1}$ \\ ${ }^{1}$ Kazan State Power Engineering University, Department of \\ Methods of Increase of Power Supply Reliability and Power Quality in \\ Distributive Electrical Grids, \\ 51 Krasnoselskaya St., Kazan, 420066, RUSSIA \\ *e-mail:vagapov@mail.ru \\ ${ }^{2}$ Institute of Physical Energetics, Laboratory of \\ Energy System Analysis and Optimisation, \\ 11 Krivu St., Riga, LV-1006, LATVIA \\ **e-mail: Iarisa.grackova@inbox.lv
}

An autonomous micro combined heat and power (Micro-CHP) is usually installed to increase energy efficiency and reduce energy costs in areas remote from large power systems. The main goal of autonomous Micro-CHP is to provide residential and industrial areas with electricity and heat. By designing an autonomous Micro-CHP, one of the key issues is the determination of rated power, since the energy efficiency of equipment and the costs of fossil fuels depend on the rated power. The mathematical model can better calculate the necessary rated power for an autonomous Micro-CHP in the case of operation with rechargeable batteries. Overall, the results have shown that the engine characteristics, operation process of threephase synchronous generator and statistical information on loads are the criteria for improving energy efficiency.

Keywords: Mathematical modelling, micro combined heat and power systems, rechargeable batteries. 
Energy efficient consumption of energy resources is one of the goals of the national energy policy for all states. Effective use of energy, as well as expansion of consumer's awareness means increasing competitiveness in the industrial sector and reducing harmful emissions into the environment. One of the objects of efficient use of energy resources is autonomous micro-CHPs on fossil fuels (diesel, gas, etc.). Micro-CHPs generate simultaneously electricity and heat, thereby saving more than $40 \%$ of fossil fuels compared to separate production of electrical and heat energy. Thus, decentralized production of electric and heat energy is economically advantageous in terms of reducing overall operating costs and carbon emissions [1]. Currently, the owners of autonomous Micro-CHPs are interested not only in production, but also in the accumulation of electrical energy in the period of time when consumption is reduced. It is the easiest way to save the generated electrical energy in high-capacity batteries (HCB). The use of rechargeable batteries for motor vehicles has significantly affected the expansion of their application in other production spheres. In particular, rechargeable batteries are already used in important power supply systems for temporary uninterrupted operation, allowing the backup diesel generators to enter a given operating mode. In addition, micro-CHP stations, such as gas piston installations (GPI), together with rechargeable batteries are fuel-saving idle-stop and switch from one mode to another, thereby reducing the wear of turbines and the efficiency of the turbine increases. It also ensures uninterrupted and efficient operation of GPI with a sharp decrease or increase in load.

The aim of this paper is to estimate the necessary rated power of autonomous Micro-CHP in the case of joint operation with high-capacity storage battery.

\section{PROFILES OF ELECTRICITY CONSUMPTION}

An autonomous Micro-CHP is customary to choose according to the rules of design and erection of electrical equipment of residential and public buildings, the standard curves of the load variation during the day and the forecast of energy consumption for the next several years. For the study, the analysis of seasonal and daily energy consumption in household, social and service sectors (statistical data from 2010 to 2019 of the Republic of Tatarstan (Russian) [2] and Latvian [3]) has been performed, which showed that the maximum power consumption occurs during the winter season.

Figures 1-3 show examples of actual load variation curves during a day for separate consumer categories in a working day, which have been chosen as they directly represent a large number of customers in the autonomous territories. The objects have been classified into three respective sectors: the household sector, the social sector and the services sector. The database of the quantitative indicators and load graphs of the six objects of each type have been investigated. Figure 1 demonstrates the household sector, i.e., consumers of private and dwelling houses. The social sector is represented by school and kindergarten consumers (see Fig. 2), while the services 
sector is made up by consumers of catering establishments and stores (see Fig. 3).

Maximum and minimum daily electric- ity consumption for each object, as well as the load factor has been determined.

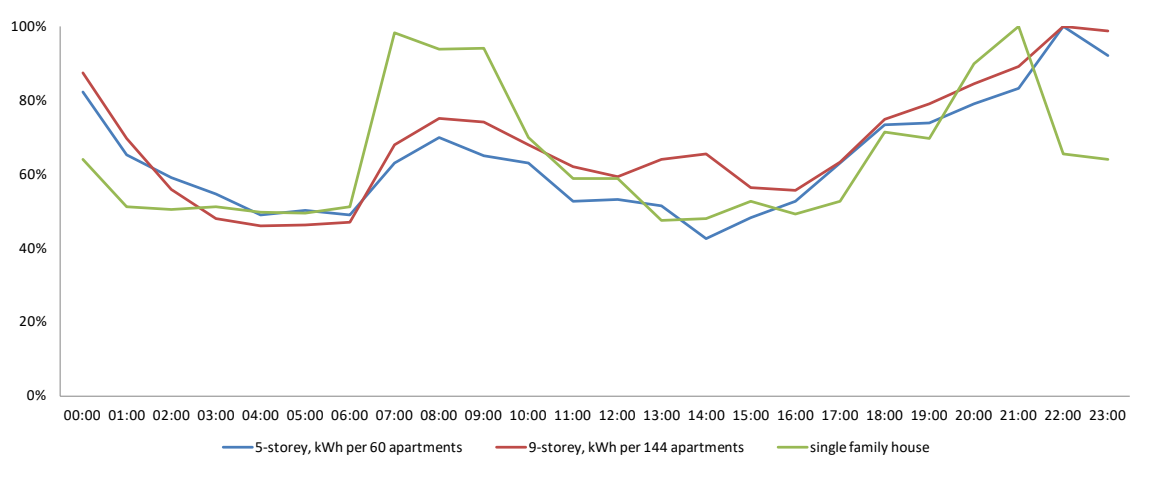

Fig. 1. Daily variation curves of the household sector.

Figure 1 shows the household sector, where we can observe that for the private house the maximum consumption is from 07:00 to $10: 00$ and from $18: 00$ to $22: 00$, the minimum consumption is from 10:00 to 18:00 and from 22:00 to 07:00. The demand factor is 0.65 . For a 5 -storey dwelling house, the maximum consumption is from 07:00 to 10:00 and from 17:00 to $01: 00$, the minimum consumption is from 10:00 to $17: 00$ and from 01:00 to 07:00. The demand factor is 0.64 . For a 9-storey dwelling house, the maximum consumption is from 07:00 to 10:00 and from 18:00 to $02: 00$, the minimum consumption is from 10:00 to 18:00 and from 01:00 to 07:00. The demand fac- tor of the household sector $\left(\mathrm{f}_{\text {dhs }}\right)$ is 0.68 .

The average maximum total loads are presented by the following values:

- 5-storey building (60 apartments)

$\mathrm{P}_{\max \text { actual }}=54 \mathrm{~kW}$;

- 9-storey building (144 apartments):

$\mathrm{P}_{\text {max actual }}=93 \mathrm{~kW}$;

- private house (with gas heating):

$\mathrm{P}_{\text {max actual }}=7.5 \mathrm{~kW}$.

For the household sector, the peak demand occurs from 07:00 to 10:00 and from 18:00 to 23:00. The calculated average demand factor of the household sector is 0.656 .

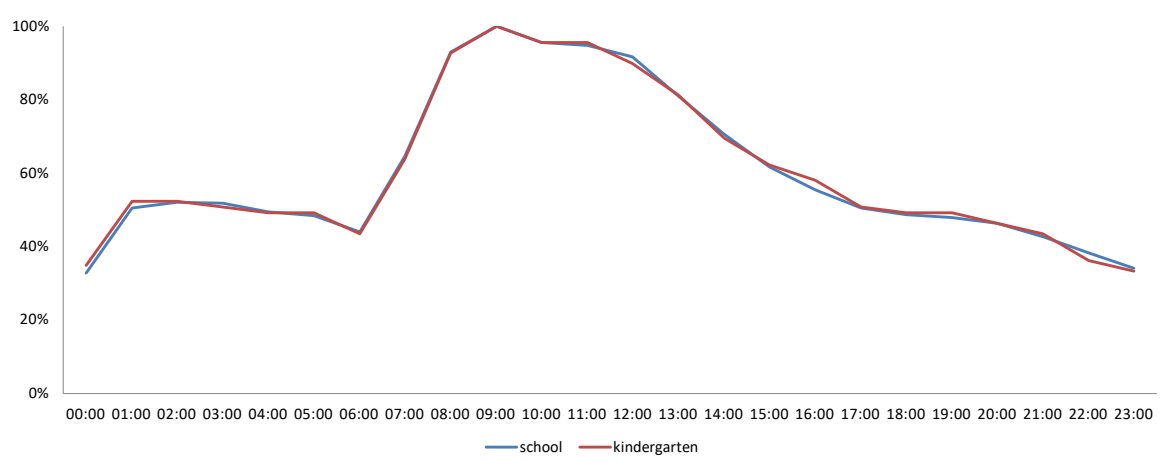

Fig. 2. Daily variation curves of the social sector. 
Comparing the results of the electricity consumption profiles shown in Fig. 2, one can see the maximum load during the period from 07:00 to 15:00 in the social sector. The demand factor of the social sector $\left(\mathrm{f}_{\text {dsocs }}\right)$ is 0.60 .

The average maximum total loads are presented by the following values:

- a school with 1852 students:

$$
\mathrm{P}_{\text {max actual }}=718 \mathrm{~kW} \text {; }
$$

- a kindergarten for 54 children:

$$
\mathrm{P}_{\text {max actual }}=176 \mathrm{~kW} \text {. }
$$

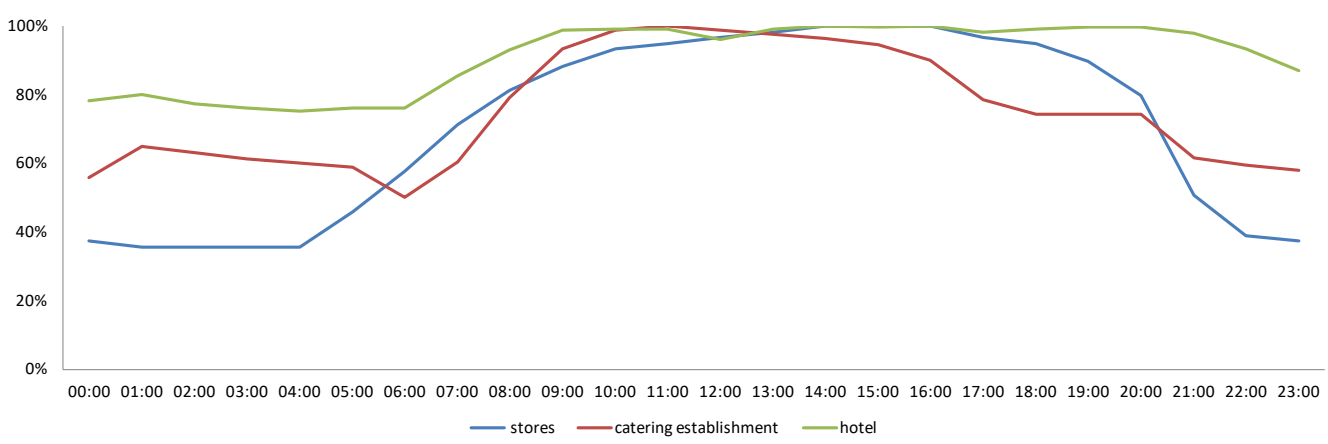

Fig. 3. Daily variation curves of the services sector.

In the services sector for the hotels the peak and on-peak demand are not expressed, the demand factor is in the range of 0.91, indicating that the load is evenly distributed throughout the day. For the catering establishments and the stores, the maximum consumption is from 07:30 to 20:30. The demand factor is 0.71 and 0.75 , respectively. The calculated average demand factor of the commercial sector $\left(f_{\text {dcs }}\right)$ is 0.79 .

The average maximum total loads are presented by the following values:

- hotel $-187 \mathrm{~m}^{2}: \mathrm{P}_{\text {max actual }}=27 \mathrm{~kW}$;

- $\quad$ store $-1500 \mathrm{~m}^{2}: \mathrm{P}_{\text {max actual }}=334 \mathrm{~kW}$;

- catering establishments $-565 \mathrm{~m}^{2}$ :

$\mathrm{P}_{\text {max actual }}=258 \mathrm{~kW}$.

All in all, it can be concluded that for the considered consumer categories the largest maximum demand of electricity is observed from 07:00 to 22:00, whereas from 23:00 to 07:00 there is the minimum demand. Granted, not all of these objects will be on at the same time but the wattage capacity needs to be there for the peak load.

The total load and the schedule on the autonomous micro combined heat and power from the consumer groups are determined by (1):

$\sum_{i=1}^{i=n} P_{i}=P_{h s} f_{d h s}+P_{\text {socs }} f_{d s o c s}+P_{s s} f_{d s s}$,

where

$P_{h s}$ is load from the household sector and $f_{d h s}$ is the average load factor from the household sector;

$P_{\text {socs }}$ is load from the social sector and $f_{\text {dsocs }}$ is the average load factor from the social sector;

$P_{s s}$ is load from the services sector and $f_{d s s}$ is the average load factor from the services sector.

The load factor $\left(f_{\text {load }}\right)$ shows the extent of use of the active power for the load curve in a specified time period and is determined by (2): 
$f_{\text {load }}=\frac{t_{1} P_{1}+t_{2} P_{2}+\ldots+t_{24} P_{24}}{\left(t_{1}+t_{2}+\ldots+t_{24}\right) P_{\max }}=\frac{1}{t P_{\max }} \int_{0}^{24} P(t)$.

According to the above-mentioned figures and expressions and also by the method of converting daily load schedules into equivalent daily two-stage schedules, the rated power of an autonomous MicroCHP can be determined.

\section{THE COMBINED USE OF AN AUTONOMOUS MICRO-CHP WITH HIGH-CAPACITY STORAGE BATTERY}

The rated power of an autonomous Micro-CHP without or with rechargeable batteries is recommended to be selected according to the expected maximum load, taking into account the technical characteristics of the engine [4].

The rated power is determined according to the profiles of electricity consumption, which have been discussed above as examples of the load of objects. When designing an autonomous Micro-CHP with high-capacity storage battery, the charge

\section{A. Mathematical Modelling}

Figure 4 shows a two-stage load graph, where $\mathrm{P}_{\mathrm{L} 1}$ is the minimum load in the time interval $\left[0 ; \mathrm{T}-\mathrm{T}_{\mathrm{m}}\right], \mathrm{P}_{\mathrm{L} 2}$ - the maximum load of duration $\mathrm{Tm}$, respectively, in the time interval $\left[\mathrm{T}-\mathrm{T}_{\mathrm{m}} ; \mathrm{T}\right]$. One of the important conditions for minimising fuel consumption for power plants during parallel operation is the distribution of the total load between them. Using the method of Lagrange multipliers for the time interval $[0 ; \mathrm{T}]$, we obtain restrictions for determining the power of high-capacity storage battery. The total fuel

$Q_{S}=Q_{1}+Q_{2}+\lambda_{1} W_{1}+\lambda_{2} W_{2}+\lambda_{3} W_{3} \rightarrow \min$,

where according to the energy balance, energy restrictions $\mathrm{W}_{\mathrm{i}}$ are written as (5): 
$\left.\begin{array}{l}W_{1}=\eta\left(P_{1}-P_{L 1}\right)\left(T-T_{m}\right)-P_{x 1}\left(T-T_{m}\right)=0, \\ W_{2}=\left(P_{2}-P_{L 2}\right) T_{m}-\eta P_{x 2} T_{m}=0, \\ W_{3}=P_{x 1}\left(T-T_{m}\right)-P_{x 2} T_{m}=0 .\end{array}\right\}$,

where $P_{x 1}$ and $P_{x 2}$ are charge power of the high-capacity storage battery (HCSB) and the HCSB discharge power, respectively, $\eta$ is the efficiency of the charge - HCSB charge process.

The joint work of the power plant and HCSB is illustrated in Fig. 4.

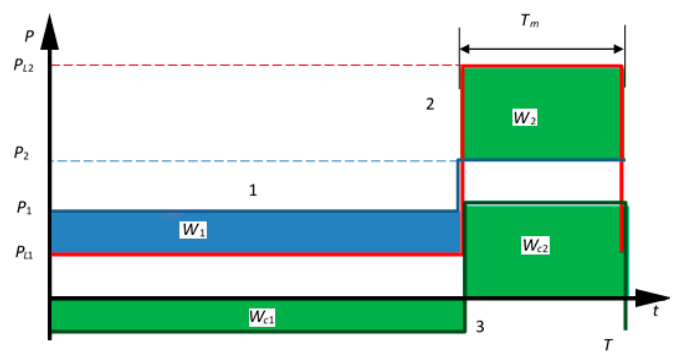

Fig. 4. Equivalent daily two-stage load schedule.

1 - power plant capacity; 2 - daily load schedule; 3 - load schedule of high-capacity storage battery; $W_{1}$ - electric power transmission from the power plant for HCSB; $W_{2}$ - electric power transmission from the HCSB for power plant; $W_{c 1}$ - power accumulated from power plant to HCSB; $W_{c 2}-\mathrm{HCSB}$ power supplied to the power plant.

The charge process of high-capacity storage battery occurs at the minimum daily load and, taking into account losses, energy storage is defined as $W_{c 1}=\eta W_{1}$. When the load increases to $P_{L 2}$, discharge occurs of the HCSB, which is additional power for autonomous Micro-CHP. The discharge process, taking into account losses, is defined as $W_{2}=\eta W c_{2}$. The capacity of high-capacity storage battery is defined as $P_{h}=P_{L 2}-P_{2}$, where $P_{2}$ is the rated power of the power plant and $P_{h}$ is the power of the HCSB.

The operating mode of the batteries has been modelled using the Simulink Simscape Power Systems (Battery block) [6]. The parameters of the Li-ion high-capacity storage battery are derived from the discharge characteristics. The discharging and charging characteristics are assumed to be the same. The maximum allowable battery depth of discharge is $20 \%$.

Applying Eqs. (4) and (5), we find the extremes Qs according to Eq. (6):

Capacity of the battery storage

$$
-\lambda_{3}=\frac{1}{\eta} \frac{\partial Q_{1}}{\partial P_{1}} \frac{1}{T-T_{m}}=\eta \frac{\partial Q_{2}}{\partial P_{2}} \frac{1}{T_{m}}
$$

Fuel consumption $q$ for each hour is determined by Eq. (7):

$$
\frac{\partial Q_{1}}{\partial P_{1}} \frac{1}{T-T_{m}}=\frac{\partial q_{1}}{\partial P_{1}}=\eta^{2} \frac{\partial q_{2}}{\partial P_{1}}=\eta^{2} \frac{\partial Q_{2}}{\partial P_{2}} \frac{1}{T_{m}} .
$$

Taking into account the restrictions for the energy balance (Eq. 5), the total capacity of the power plant in time intervals is determined by:

$P_{2}=P_{L 2}+\frac{\left(P_{L 1}-P_{1}\right)}{\rho}, \rho=\frac{T_{m}}{\eta^{2}\left(T-T_{m}\right)}$ and $P_{x 2}=\frac{P_{L 2}-P_{2}}{\eta}$, 
where $\rho$ is a relative value of the duration of the maximum load and $P_{x 2}$ is maximum power of HCSB in the discharge mode.

The total installed capacity of an autonomous Micro-CHP with rechargeable batteries and the optimum load are calculated using Eq. (7). The fuel rate in the analytical formula is defined as $q=a+b P^{\mu}$ (litre/ hour). Based on the fuel consumption characteristics of a particular power plant
(Block 1), a three-phase synchronous generator (Block 3) and actual load (Block 5) approximation coefficients $\mathrm{a}, \mathrm{b}$ and $\mu$ are selected. For this purpose, using Simulink Simscape Power Systems, the distribution network has been modelled and tested in the discrete mode (see Fig. 5).

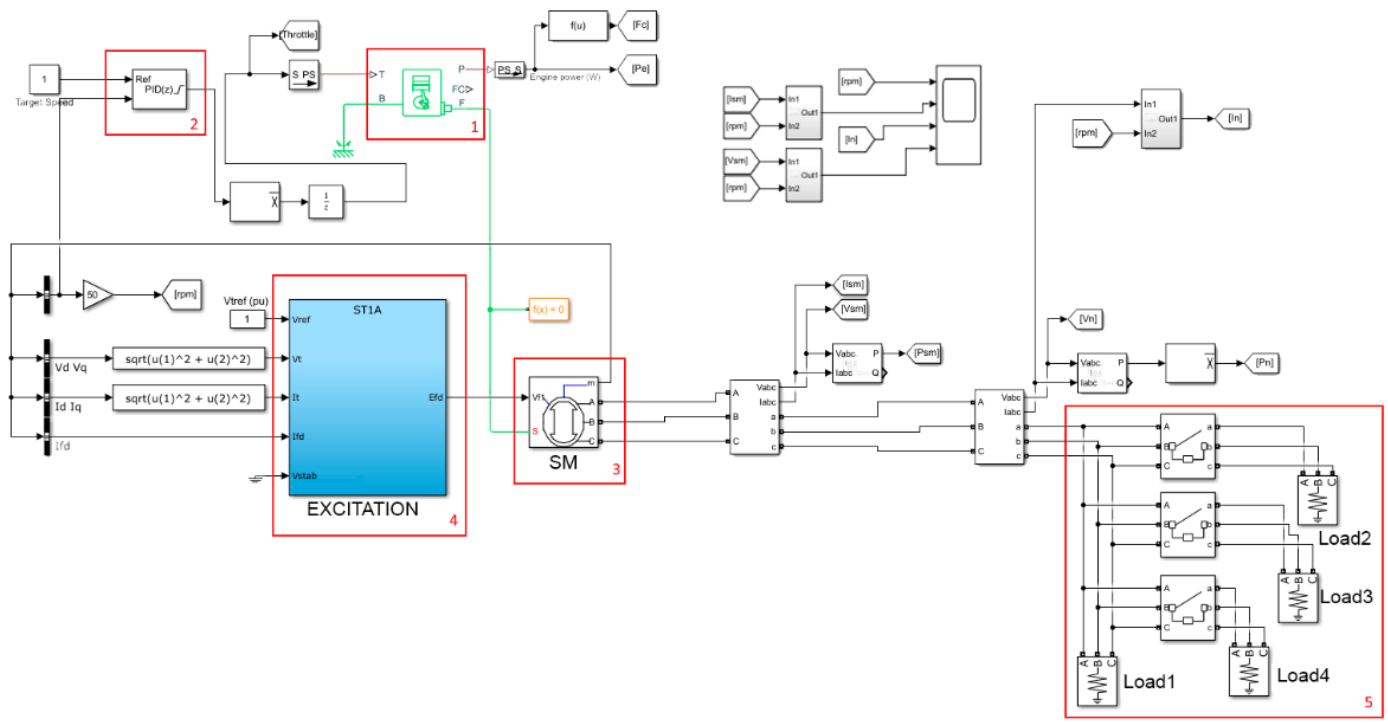

Fig. 5. Distribution network model "Engine - three-phase synchronous generator-Load".

Block 1: Engine characteristics definition.

Block 2: Differential controller of engine speed.

Block 3: Three-phase synchronous generator.

Block 4: Generator excitation system.

Block 5: Actual load: $100 \%, 75 \%, 50 \%$ and $25 \%$.

Then, minimum power plant $P_{l}$ is determined as the correlation between the generated power at the minimum fuel consumption and time intervals:

$$
P_{1}=\eta^{2 / \mu-1} P_{2} \text {. }
$$

Applying Eq. (8), the maximum power plant $\left(P_{2}\right)$ is determined by:

$P_{2}=\frac{P_{L 1}+\rho P_{L 2}}{\eta^{2 / \mu-1}+\rho}=P_{L 2} \frac{k_{m}^{-1}+\rho}{\eta^{2 / \mu-1}+\rho}$, where $k_{m}=\frac{P_{L 2}}{P_{L 1}}$ 
Total fuel consumption $Q s$ in the time

$Q_{s}=a T+b\left[P_{1}^{\mu^{*}}\left(T-T_{m}\right)+P_{2}^{\mu^{*}} T_{m}\right]$.

Thus, we can conclude that Eq. (7)-(11) allow determining the rated power of the

\section{B. Math Model Testing}

Thus, to validate the mathematical model, two work modes have been simulated:

- Work mode A is a model of the autonomous Micro-CHP (diesel generator DOOSAN DP158LD, 0.424 MW rated power);

- Work mode B is a model of the autonomous Micro-CHP diesel generator DOOSAN DP158LD, 0.424 MW rated power) with rechargeable batteries.

The input data of mode $\mathrm{A}$ are as fol- interval $[0 ; \mathrm{T}]$ is calculated as follows:

power plant with minimum fuel consumption $\left(Q_{s}\right)$. lows: $\mathrm{P}_{2}=0.422 \mathrm{MW} ; \mathrm{km}=5 ; \mathrm{T}=24$ hours; $\mathrm{T}_{\max }=4$ hours. $\mu=1.45$ (p.u); $\mathrm{a}=22.31$ (liter/hour); $b=368.57$ (liter/kWh) and $25 \%$ actual load.

On the basis of this information, the minimum daily load for the temporary daily intervals is calculated by Eq. (10). Therefore, $\mathrm{P}_{\mathrm{L} 1}=0.4 / 5=0.08 \mathrm{MW}$ and $\mathrm{P}_{\mathrm{L} 2}=0.4$ MW.

The total fuel consumption Qs in the time interval [ $\mathrm{T}-\mathrm{Tm}$; $\mathrm{T}]$ has been defined by Eq. (11):

$$
Q_{s}=22.31 \cdot 24+368.57\left[0.08^{1.45} \cdot(24-4)+0.4^{1.45} \cdot(24-4)\right]=1115 \text { liter }
$$

Further, taking into account input data of mode $\mathrm{A}$ and the main characteristics of Lithium-Ion (Li-Ion) rechargeable batteries (where $\eta^{2}=0.9, \rho=0.222$ and $\eta^{2 / \mu-1}=$ $0.791)$, mode B has been calculated.

Applying Eq. (8), the maximum power plant $\left(P_{2}\right)$ is determined as follows:

$$
P_{2}=0.4 \frac{5^{-1}+0.222}{0.791+0.222}=0.167 M W
$$

The minimum power plant $\left(P_{l}\right)$ is estimated by Eq. (9):

$$
P_{1}=0.791 \cdot 0.167=0.132 \mathrm{MW} .
$$

The results show that it is necessary to use a diesel generator of lower power. Since, according to the requirements of the operating conditions, the power plant of the diesel generator must have a power reserve of at least $30 \%$ of the required consumption, diesel generator G299BDGR (0.217 MW rated power) has been selected from the list of industrial diesel generators.

However, when the load increases to $\mathrm{P}_{\mathrm{L} 2}=0.4 \mathrm{MW}$, the process of discharge of the HCSB is carried out. In our case, the capacity of high-capacity storage battery is defined by Eq. (10): 
$P_{x 2}=\frac{0.4-0.167}{0.95}=0.246 \mathrm{MW}$.

According to the requirements of the manufacturers, for maximum life, the battery should not be discharged by more than $40 \%$. Therefore, LT-LYP 380 lithium iron phosphate batteries have been selected. In our case, the discharge process takes place within four hours and the charging process will be carried out within 20 hours a day.

Total fuel consumption $Q s$ in the time interval $[0 ; \mathrm{T}]$ is calculated as follows:

$Q_{s}=22.31 \cdot 24+368.57\left[0.132^{1.45} \cdot(24-4)+0.167^{1.45} \cdot(4)\right]=1035$ liter

The calculations above allow concluding that when using rechargeable batteries at peak loads, it will be enough to install diesel generators with a capacity of 0.217 MW, which will reduce diesel consumption by 68 tonnes per day or 24820 tonnes per year. In addition, using a high-capacity storage battery results in a reduction of diesel fuel costs of about $€ 14.15$ million per year. In turn, this also leads to emission reduction, i.e., a decrease in 78.15 thousand tons of $\mathrm{CO}_{2}$ emissions each year (see Table 1).

Table 1. Output Data of Mode A and Mode B

\begin{tabular}{|l|c|c|}
\hline & Work mode A & Work mode B \\
\hline Qs, kt/year & 345.93 & 321.11 \\
\hline Qs, TJ/year & 14698.51 & 13643.91 \\
\hline $\begin{array}{l}\text { Qs, EUR million per year. } \\
\text { Diesel fuel price per 1 tonne = 570 EUR. April 2020. [7] }\end{array}$ & 197.18 & 183.03 \\
\hline CO2, kt/year [8] & 1089.160 & 1011.014 \\
\hline
\end{tabular}

Comparing the results of the modelled modes of the data on the fuel consumption, one can see that mode 2 is favourable as to the fuel consumption and $\mathrm{CO}_{2}$ emissions from fossil fuel. Fuel consumption and $\mathrm{CO}_{2}$ emissions decreased by $7.2 \%$ using a diesel generator of lower power.

The results of the modelled modes allow concluding that despite a similar load it is possible to cut fuel consumption and the volume of relevant emissions.

It should be noted that in the framework of the implementation of the project "Methods to Improve the Reliability of
Power Supply Systems and the Quality of Electricity Based on Electrochemical Storage Devices and Digital Monitoring of the State of Distribution Electric Networks", an autonomous Micro-CHP with rechargeable batteries has been commissioned (Tomsk Region, federal subject of Russia, 2019). The main parameters of Micro-CHP are as follows: Caterpillar 3512 Diesel Generator, $0.980 \mathrm{MW}$ rated power, average fuel consumption is 280 litre/hour; LiFePO4 batteries, 0.3 MVA installed capacity. Some images of the object are shown in Fig. 6. 


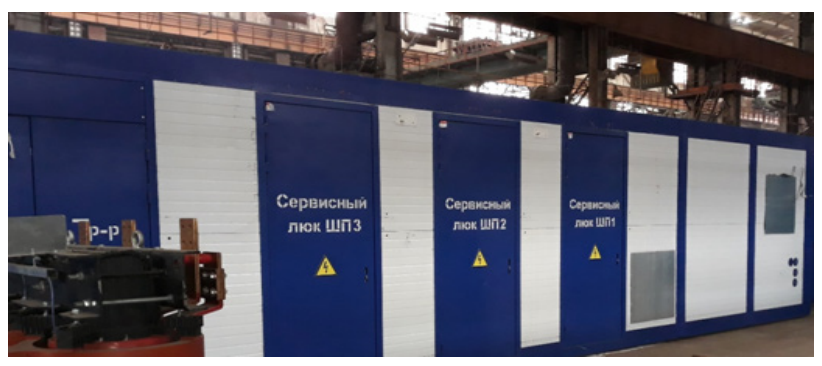

An autonomous Micro-CHP
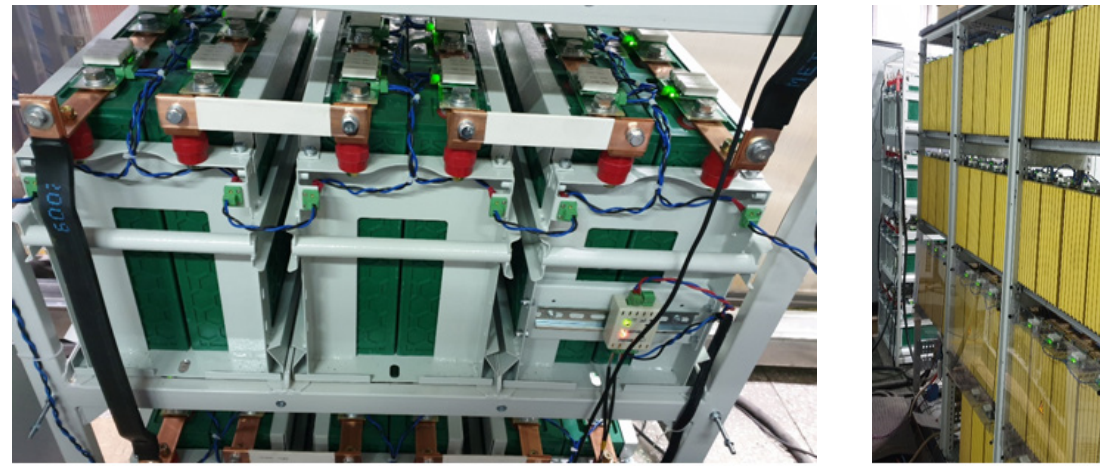

Battery configurations in sections

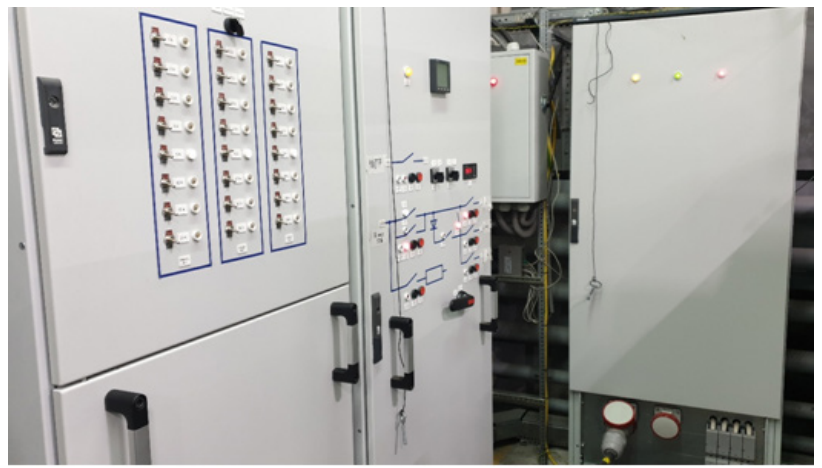

The control switchboard

Fig. 6. The images of autonomous Micro-CHP.

\section{CONCLUSION}

Choosing the capacity and planning the operation of an autonomous Micro-CHP must be based on technical and statistical information on loads. This means that equipment and energy resources will be used efficiently.
Taken together the theoretical and practical studies, it has been found that the efficient operation process of the autonomous Micro-CHP diesel generator and highcapacity storage battery can save fossil fuel and thereby reduce $\mathrm{CO}_{2}$ emissions. 
To make decisions on investment in an autonomous Micro-CHP diesel generator with high-capacity storage battery projects, it is necessary to consider a number of additional parameters that have not been examined in the article, for example, capital investments in a specific project to make forecast of fossil fuel cost for the next ten years. The variation in fossil fuel cost is influenced by a number of factors, such as social and economic changes in the country, world prices for fossil fuels, the tax system, etc.
The mathematical modelling considered in the article makes it possible to recognise this option of energy supply as effective in those areas where building the high voltage transmission and distribution lines is not economically profitable.

It should also be noted that for areas located close to the places of crude oil production, it is advisable to use associated gas as fuel, since here this type of fuel will have minimum cost. In terms of the investment and fossil fuel saving, substantial benefits could accrue.

\section{ACKNOWLEDGEMENTS}

The research has been supported by the Ministry of Science and Higher Education of the Russian Federation on fundamental scientific research "Distributed automated systems for monitoring and diagnostic the technical condition of overhead power lines and substations based on technology of broadband data transmission through power lines and the Industrial Internet of Things" (theme mnemonic code 0672-2020-0009, Agreement 075-03-2020-178).

\section{REFERENCES}

1. Mutule, A., \& Teremranova, J. (2018). Introduction of Energy Saving Principles: Technologies and Awareness, Latvian Experience. Latvian Journal of Physics and Technical Sciences, 55 (6), 52-62. DOI: 10.2478/lpts-2018-0044

2. Network Company. The Distribution System Operator in the Republic of Tatarstan. (n.d.) Retrieved 4 April 2020 from http:// www.gridcom-rt.ru/o-kompanii/obshchayainformatsiya

3. Latvenergo Group. (n.d.) Retrieved 5 December 2018 from http://www.latvenergo. lv/portal/page/portal/Latvian/Sad_tikls/ Tipveida+grafiki_jauns.htm

4. Genmotors. (n.d.) Available at https:// kazan.dizelnye-generatory.com/dizelnyegeneratory/g584dsgr-grupel/
5. Promelektroautomatika. (n.d.) Available at http://www.pea.ru/docs/equipment/batteries/ lioteh/

6. MathWorks. Simulink Simscape Power Systems (SimPowerSystems). Available at https://uk.mathworks.com/products/ simpower.html

7. GlobalPetrolPrices.com. (n.d.) Available at https://www.globalpetrolprices.com/Russia/ diesel_prices/

8. 2006 IPCC Guidelines for National Greenhouse Gas Inventories. Chapter 2: Stationary Combustion. (n.d.). Available at www.ipcc-nggip.iges.or.jp/public/2006gl/ pdf/2_Volume2/V2_2_Ch2_Stationary_ Combustion.pdf 